\title{
Thyroid Function, Cardiac Risk Assessment Profile and Hematological Changes During HIV Infection and AIDS Patients
}

\author{
PALANI SAMY PASUPATHI ${ }^{1}$, PERISAMY MANIVANNAN² ${ }^{2}$, UMA MANIVANNAN ${ }^{3}$, MATHIYALAGAN DEEPA ${ }^{1}$
}

\begin{abstract}
Background: The aim and objective of this study was to investigate the level of serum lipids and thyroid hormones status in HIV infection and AIDS patients.

Methods: The population consisted of I 50 subjects divided into three groups; among HIV infected patients fifty cases, AIDS patient's fifty cases and an equal numbers of age- and sex-matched healthy subjects were investigated.

Results: In this study, we observed the level of serum lipids significant changes occur in AIDS patients compare to HIV infection and healthy subjects. There were no significant differences in total TT4 concentrations among the AIDS patients when compared to HIV infection and normal healthy subjects. A measured FT4 concentration was slightly but significantly decreased in HIV IAIDS patients. Total T3 concentrations were normal in HIV infected patients, but slightly decreased in AIDS; more important, T3 level was decreased in AIDS patients. The level of FT3 concentration was slightly but significantly increased in HIV infected and significantly decreased in AIDS patients. As all TSH levels were within the normal range; however, there was a small but significantly increase in TSH levels in AIDS, and there was a trend toward an increase in TSH levels in AIDS compared with controls.

Conclusion: Thyroid dysfunction is frequent in HIV infection and with progression of disease there is a primary hypothyroid like stage that occurs in patients with HIV infection. TT3, FT3, FT4 and serum TSH can be used as a surrogate marker of the progression of the disease.
\end{abstract}

Key word: HIV, AIDS, CD4+ cell count, Thyroid function test, Lipids, Hematological Test

\section{Introduction}

The acquired immunodeficiency syndrome (AIDS), is a fatal illness caused by a retrovirus known as the human immunodeficiency virus that breaks down the body's immune system, infects CD4+ cells initially and progressively leads to AIDS. ${ }^{1}$ There are 2.47 million persons in India living with HIV; equivalent to approximately $0.36 \%$ of the adult population. ${ }^{2}$ The revised national estimate reflects the availability of improved data rather than a substantial decrease in actual HIV prevalence in India. The transmission route is still predominantly sexual $(87.4 \%)$; other routes of transmission by order of proportion include prenatal (4.7\%), unsafe blood and blood products $(1.7 \%)$, infected needles and syringes $(1.8 \%)$ and unspecified routes of transmission $(4.1 \%){ }^{3}$

Men with HIV infection were reported to have hypocholesterolemia with and without hypertriglyceridemia. ${ }^{4,5}$ An association between plasma triglyceride and circulating interferon-levels has been observed in persons with AIDS.
However, the mechanism for hypocholesterolemia in HIV and other infections is not known. A pattern of hyperlipidemia (i.e. elevated levels of total cholesterol, lowdensity lipoprotein cholesterol, and triglycerides, and a reduced level of high-density lipoprotein cholesterol) has been observed in patients treated with protease inhibitors. ${ }^{6,7}$ Infection can increase plasma triglyceride levels by decreasing the clearance of circulating lipoproteins, a process considered to be the result of reduced lipoprotein lipase (LPL) or by stimulating hepatic lipid synthesis through increases in either hepatic fatty acid synthesis or reesterification of fatty acid derived from lipolysis. ${ }^{8}$ Hypertriglyceridaemia was the first dyslipidaemia to be reported in HIV infected patients, but other lipid abnormalities such as hypocholesterolaemia or hypo HDL cholesterolaemia have also been reported.

The CD4+ lymphocyte is the primary target of HIV infection because of the affinity of the virus to the CD4+ surface marker. Infection with HIV leads to a progressive impairment

1. CRISTAL Diagnostic \& Research Laboratory (CDRL), Sri Sugam Hospital Compos, Omalur, Salem-636 455, Tamil Nadu, India

2. Department of General Medicine, Diabetologe

3. Department of Gynecology, Sri Sugam Hospital, Omalur, Salem-636 455, Tamil Nadu, India

Correspondence: Dr. P. Pasupathi, Head- Laboratory Medicine, CRISTAL Diagnostic \& Research Laboratory (CDRL), Sri Sugam Hospital Compos, 149E, Bazaar Street-Omalur, Salem-636 455, Tamil Nadu, India, E-mail: drppasupathi@gmail.com 
of cellular functions, characterized by a gradual decline in peripheral blood $\mathrm{CD}^{4+}$ lymphocyte levels which results in an increasing susceptibility to a wide variety of opportunistic, viral, bacterial, protozoal, and fungal infections and to certain malignancies also. ${ }^{7}$ Thus HIV can make copies of its own genome as DNA in the host's cells such as human T4-helper lymphocytes and this leads to the elaboration of vast numbers of viral particles. Although immunological dysfunction is common to all AIDS patients, the clinical spectrum of HIV infection is diverse and multiple organ involvement is frequently evident.

Increasing experience with this syndrome has led to the recognition of a variety of HIV related endocrine disorder that occurs during both the early and late stages of the disease. Among these disorders a high prevalence of abnormalities in thyroid function tests is reported in previous cross-sectional studies. Unique abnormalities of thyroid function tests were reported by Lambert et al. ${ }^{9}$ They described a progressive elevation in serum thyroxin binding globulin (sr.TBG) but not in other binding proteins such as cortisol binding globulin (CBG) that accompanies a decline in CD4+ count with advancing HIV infection. FeldtRasmussen et al. reported elevation of sr. TSH and s. TBG concentration in conjunction with low FT-4 that occurs frequently and correlates with CD4+ cell depletion in AIDS patients. ${ }^{10}$ In addition, this thyroid dysfunction correlated with the degree of immunosuppression and viral replication and preceded the worsening of the disease. Subtle alterations in thyroid function tests (TFT) are more common in HIV infection and are sometimes already detectable in the early phase of disease. The changes in thyroid function tests are HIV specific and are consistent with an abnormal response to acute illness. Various mechanisms have been proposed to explain such abnormalities in TFT. ${ }^{11}$ These include direct infection of thyroid gland by opportunistic organisms such as Pneumocystis carinii, infiltration of the gland by tumors such as Kaposi sarcoma, effect of humoral factors such as IL- $1 \alpha$ and TNF- $\alpha$, side effect of the drugs used in the course of HIV infection for e.g. rifampicin, ketoconazole, steroids etc. and direct infection of gland by HIV. Thus we studied a spectrum of newly diagnosed HIV+ patients from asymptomatic to AIDS who were not receiving HAART. The present study was undertaken to examine the changes in lipid, CD4+ T cell counts and thyroid hormone changes in HIV infection, AIDS patients and HIV-negative controls.

\section{Materials and Methods}

\section{Study Population}

The population consisting of 150 subjects divided into three groups was selected. The objective of this study was to investigate lipids and thyroid hormones [total T3, T4, FT3, FT4 and TSH] status among HIV infected patients 50 cases $(n=50)$, AIDS patients 50 cases $(n=50)$ and an equal numbers of age- and sex-matched control subjects $(n=50)$ were investigated. The prospective study was carried out at the Sri Sugam Hospital and Sai Bhrenthavan Homeo Clinic, Salem, Tamil Nadu, India from January 2008 to January 2010. For diagnosis and confirmation of HIV infection, we followed the National AIDS Control Organization (NACO) recommendations for HIV testing NACO. ${ }^{4}$ All the patients were subjected to detailed history taking and clinical examination. Informed consent of the patients was taken before testing. Individuals were classified according to the Centers for Disease Control and Prevention Criteria (CDC) classification system that emphasizes the importance of CD4 ${ }^{+}$ T lymphocyte testing in clinical management of HIV-infected persons. The system is based on three ranges of CD4 counts (1) $>500 \mathrm{~mm}^{-3}$; (2) 200-499 $\mathrm{mm}^{-3}$; and (3) $<200 \mathrm{~mm}^{-3}$. 12

Classification of the values into raised, low or normal thyroid hormone levels were based on the following criteria. Subjects classified as having raised level of thyroid hormones: had FT4 values $>1.6 \mathrm{ng} / \mathrm{l}$ or, TSH $<0.4 \mathrm{miu} /$ or both, those classified as having low level had FT4 values $<0.68 \mathrm{ng} / \mathrm{ml}$, or TSH values $>5.0 \mathrm{miu} / \mathrm{ml}$, or both. Subjects grouped as normal had FT4 and TSH values within the range $>0.68-1.6 \mathrm{ng} / \mathrm{ml}$, and $0.4-5.0 \mathrm{miu} / \mathrm{ml}$ respectively.

\section{Sample collection}

Single sample of 10-ml. ante-cubical venous bloods was obtained with all aseptic measure. After let to clot, the blood was centrifuged for 30 minutes and the supernatant (serum) was taken in a separate test tube. Thus the serum was ready and used for hormone analysis in the laboratory.

\section{Biochemical investigation}

The levels of serum thyroid stimulating hormone (TSH), total triiodothyroxine (T3), free thyroxine (FT4) and free triiodothyronine (FT3) were measured by a Microparticle Enzyme Immunoassay (MEIA) on AXSYM System (Abbott Laboratories, Abbott Park, USA) while serum total thyroxine (T4) was measured by the Fluorescence Polarization Immunoassay (FPIA) method on AXSYM System using the standard laboratory methodologies. Serum lipids were determined using fully automated clinical chemistry analyzer (Hitachi 912, Boehringer Mannheim, Germany). Red blood cell count, total white blood cell count, platelet count, total hemoglobin, hematocrit and ESR were determined using fully automated hematology analyzer (Pentra-XL 80, Horiba ABX, USA). The $\mathrm{CD}^{4+}$ lymphocyte count was estimated by Fluorescence Activated Cell Sorter (FACS) count system (Becton Dickinson, USA). 


\section{Statistical analysis}

All data were expressed as mean \pm SD. The statistical significance was evaluated by Student's t test and the MannWhitney U-test was used. Statistical analyses were performed with Statistical Package for Social Sciences software (SPSS Cary, NC, USA) version 10.0. A p value of less than $<0.05$ was considered statistically significant.

\section{Results}

Information about the investigated characteristics is shown in Table I. The mean age limit was $49 \pm 13.4$ in AIDS patients, $47 \pm 10.2$ in HIV infected patients and $48 \pm 9.3$ in control subjects. The decrease in body mass index in AIDS patients $\left(22.5 \pm 6.9 \mathrm{~kg} / \mathrm{m}^{2}\right)$ compared with HIV infected patients $(30.8$ $\left.\pm 7.1 \mathrm{~kg} / \mathrm{m}^{2}\right)$ and control subjects $\left(32.7 \pm 6.7 \mathrm{~kg} / \mathrm{m}^{2}\right)$ were statistically significant. On the other hand the drastically decreased body mass index in AIDS patients compare with HIV infection was highly significant. The increased number of hypertension, smokers and alcoholics were observed in AIDS patients compared with HIV infection and control subjects.

Table II shows the levels of $\mathrm{CD}^{4+}$ cell count, total RBC count, WBC count, platelet count, hemoglobin, hematocrit and ESR in control, HIV infected and AIDS patients. The levels of $\mathrm{CD}^{4+}$ cell count, total RBC count, platelet, hemoglobin and hematocrit were significantly decreased in AIDS patients when compared with HIV infected patients and control subjects. On the other hand, the level of total WBC count and ESR were significantly increased in HIV infected and AIDS patients. The above-mentioned hematological parameters were found to be more significantly altered in AIDS patients compared with HIV infected subjects.

Table III shows the lipids level changes in HIV infected patients, AIDS patients and normal healthy subjects. The levels of total cholesterol, HDL and LDL were significantly decreased, while the level of triglyceride and VLDL were significantly increased in AIDS patients when compared to HIV infected patients and normal subjects, but the levels of VLDL in the HIV infected patients and control subjects did not differ significantly.

Table IV showing the level of thyroid hormone (TT3, TT4, FT3, FT 4 and TSH) changes in normal healthy subjects, HIV infection and AIDS patients. There were no significant differences in total TT4 concentrations among the AIDS patients when compared to HIV infection and normal healthy subjects. A measured FT4 concentration was significantly decreased in HIV infected and AIDS patients. Total T3 concentrations were normal in HIV infected patients, but decreased in AIDS; more important, T3 level was decreased in AIDS patients. The level of FT3 concentration was significantly increased in HIV infected and significantly decreased in AIDS patients. As all TSH levels were within the normal range; however, there was a small but significantly increase in TSH levels in AIDS, and there was a trend toward an increase in TSH levels in AIDS compared with controls.

Table-I

Demographic characteristics of different study group.

\begin{tabular}{lccc}
\hline Parameter & Control subjects & HIV infection & AIDS patients \\
\hline Total number of subjects $(\mathrm{n})$ & 50 & 50 & 50 \\
Sex (male) & $100 \%$ & $100 \%$ & $100 \%$ \\
$\quad$ Mean age (mean $\pm \mathrm{SD}$; years) & $48 \pm 9.3$ & $47 \pm 10.2^{\mathrm{NS}}$ & $49 \pm 13.4^{* \ddagger}$ \\
$\quad$ Body mass index $\left(\mathrm{kg} / \mathrm{m}^{2}\right)$ & $32.7 \pm 6.7$ & $30.8 \pm 7.1 \mathrm{NS}$ & $22.5 \pm 6.9^{*}$ \\
Risk factors & & & \\
Hypertension & $10 \%$ & $70.5 \%$ & $87.5 \%$ \\
Smokers & $11 \%$ & $53 \%$ & $85 \%$ \\
Alcoholics & & $60 \%$ & $80 \%$ \\
\hline
\end{tabular}

Values are given as mean \pm S.D from fifty subjects in each group.

*AIDS patients compared with control subjects

* AIDS patients compare with HIV infection

NS - Non significant; $p<0.05$ considered statistically significant. 
Table-II

Blood picture of the subjects investigated.

\begin{tabular}{lccc}
\hline Parameter & Control subjects & HIV infection & AIDS patients \\
\hline RBC count $\left(10^{6} / \mu \mathrm{l}\right)$ & $6.0 \pm 0.54$ & $4.9 \pm 0.85^{\dagger}$ & $2.9 \pm 0.82^{* \dagger}$ \\
WBC count $\left(10^{6} / \mu \mathrm{l}\right)$ & $7.5 \pm 1.5$ & $10.1 \pm 2.1^{\dagger}$ & $12.5 \pm 2.8^{* \dagger}$ \\
CD4+ cell count $(\mathrm{Cells} / \mu \mathrm{l})$ & $820 \pm 97$ & $394 \pm 68^{\dagger}$ & $191 \pm 42^{*}$ \\
Hemoglobin $(\mathrm{g} / \mathrm{dl})$ & $15.2 \pm 1.3$ & $11.9 \pm 1.5^{\dagger}$ & $8.7 \pm 1.7^{*}$ \\
Hematocrit $(\%)$ & $46.1 \pm 4.0$ & $35.7 \pm 3.7^{\dagger}$ & $26.8 \pm 3.2^{* \dagger}$ \\
Platelet count $\left(\mathrm{Cells} / 10^{3} \mu \mathrm{l}\right)$ & $315 \pm 50$ & $100 \pm 41^{\dagger}$ & $40 \pm 32^{* \hbar}$ \\
ESR $(\mathrm{mm} / \mathrm{hr})$ & $8 \pm 2.1$ & $91 \pm 22^{\dagger}$ & $221 \pm 42^{*}$ \\
\hline
\end{tabular}

Values are given as mean \pm S.D from fifty subjects in each group.

*AIDS patients compared with control subjects

${ }^{\dagger}$ HIV infection compare with control subjects

* AIDS patients compare with HIV infection

$p<0.05$ considered statistically significant.

Table-III

Changes in the level of total cholesterol, triglyceride, HDL, LDL and VLDL in control, HIV infection and AIDS patients

\begin{tabular}{lccc}
\hline Parameter & Control subjects & HIV Infection & AIDS patients \\
\hline Total cholesterol $(\mathrm{mg} / \mathrm{dl})$ & $154 \pm 25.7$ & $141 \pm 23.5^{\mathrm{NS}}$ & $118 \pm 26.3^{* \neq}$ \\
Triglyceride $(\mathrm{mg} / \mathrm{dl})$ & $92 \pm 15.5$ & $231 \pm 25.0^{\dagger}$ & $351 \pm 35.1^{* \neq}$ \\
HDL-cholesterol $(\mathrm{mg} / \mathrm{dl})$ & $53 \pm 7$ & $30 \pm 6.1^{\dagger}$ & $19 \pm 5.9^{* \neq}$ \\
LDL-cholesterol $(\mathrm{mg} / \mathrm{dl})$ & $53 \pm 10$ & $75 \pm 14.2^{\dagger}$ & $181 \pm 20.2^{* \neq}$ \\
VLDL-cholesterol $(\mathrm{mg} / \mathrm{dl})$ & $18 \pm 5$ & $46 \pm 9^{\dagger}$ & $72 \pm 12^{* \neq}$ \\
\hline
\end{tabular}

Values are given as mean \pm S.D from fifty subjects in each group

*AIDS patients compared with control subjects

${ }^{\dagger}$ HIV infection compare with control subjects

* AIDS patients compare with HIV infection

NS-Not significant; $p<0.05$ considered statistically significant

\section{Discussion}

The present study showed that lipid profile was altered in HIV infected and AIDS patients. Alteration in the lipid profile occurred even during the early stages of HIV infection and, more so, as the disease progressed. This high number of AIDS cases and the fact that there were no patients in clinical stage in our study could be due to the fact that patients with HIV infection seek hospital admission only in the late clinical stages when they have opportunistic infections. ${ }^{4}$

Previous studies have demonstrated that patients with AIDS exhibit highly abnormal total lipid concentrations in plasma. ${ }^{13}$ A few authors have determined the levels of plasma triglycerides, total cholesterol and HDL cholesterol in HIV infected individuals by the level of immunological deficiency according to the CD4+ cell count, also came to the same conclusion that, with an increase of immunological deficiency and clinical development of HIV infection, lipid profile disorders, indicated by an increase in triglyceride level and decreased concentrations of HDL cholesterol intensified as well. ${ }^{14}$ Consistent with earlier reports, our study also showed similar findings in which the decrease of CD4+ count due to disease progression was accompanied by decrease in total cholesterol, HDL and LDL, and increase in triglyceride and VLDL levels.

Our findings are also consistent with reports from Ducobu and Payen, who stated that HIV infection induced an early decrease of cholesterol and a late increase of triglyceride with a reduction of HDL. ${ }^{14}$ These changes were proportional 
Table-IV

Showing mean \pm SE of TT3, TT4, FT3, FT 4 and TSH in control, HIV infection and AIDS patients

\begin{tabular}{lccc}
\hline \multicolumn{1}{c}{ Parameter } & Control subjects & HIV Infection & AIDS patients \\
\hline TT3 $(\mathrm{ng} / \mathrm{ml})$ & $1.02 \pm 0.24$ & $1.15 \pm 0.22^{\mathrm{NS}}$ & $0.67 \pm 0.49^{* \sharp}$ \\
TT4 $(\mu \mathrm{g} / \mathrm{dl})$ & $7.71 \pm 2.32$ & $8.02 \pm 2.16^{\mathrm{NS}}$ & $7.95 \pm 2.08^{\mathrm{NS}}$ \\
FT3 $(\mathrm{pg} / \mathrm{ml})$ & $2.45 \pm 0.79$ & $3.57 \pm 1.21$ & $2.72 \pm 1.05^{* \ddagger}$ \\
FT4 $(\mathrm{ng} / \mathrm{ml})$ & $1.39 \pm 0.47$ & $1.15 \pm 0.99$ & $0.97 \pm 0.27^{*}$ \\
TSH $(\mathrm{mIU} / \mathrm{ml})$ & $1.95 \pm 0.73$ & $2.12 \pm 0.62^{\mathrm{NS}}$ & $3.37 \pm 1.23^{* \ddagger}$ \\
\hline
\end{tabular}

Values are given as mean \pm S.D from 50 subjects in each group.

*AIDS patients compared with control subjects

HIV infection compare with control subjects

* AIDS patients compare with HIV infection

NS-Not significant; $p<0.05$ considered statistically significant

to the lowering of $\mathrm{CD}^{4+}$ count, which reflected the severity of infections, as was the case in our study. However, some authors reported that patients with AIDS had increased levels of LDL cholesterol, which contradicted our findings. ${ }^{14}$ This low level of total cholesterol, HDL and LDL was reported to be associated with elevated levels of $\alpha-2$ microglobulin. Low cholesterol levels are prevalent even during early stages of HIV and associated with a specific alteration in immune function. Kereveur et al. stated that hypocholesterolaemia observed in early and hypertriglyceridaemia in later stage of the infection are due to cytokine effects on different enzymes of lipid metabolism. ${ }^{15}$

Grunfeld et al. had reported that HIV/AIDS characterized by a high prevalence of hypertriglyceridaemia and hypocholesterolaemia, and also an elevated level of cytokines. ${ }^{8}$ They observed decreased cholesterol and cholesterol containing lipoproteins in both AIDS and HIV infection precede the appearance of hypertriglyceridaemia. Increased TG levels in AIDS were primarily due to increase in VLDL. They also raised the possibility that with the development of AIDS, subsequent increase in IFN may have contributed to increase in plasma triglyceride levels by decreasing the clearance of TG. The increase of triglyceride catabolism in relation to reduction of lipoprotein lipase activity was responsible for these lipid changes. Many cytokines such as IFN, IL and TNF probably play a pathogenic role in the dyslipedaemia of HIV. ${ }^{16}$ Hence it may be suggested that lipid profile can be a good index of disease progression in HIV infection and AIDS patients.

Hematological abnormalities are among the most common complications of infection with HIV. Depending on the study setting, anemia can be found in $63-95 \%$ of those with HIV infection at some point during the course of their disease. ${ }^{17}$ Chronic thrombocytopenia develops in approximately one third of individuals infected with human immunodeficiency virus during the course of acquired immunodeficiency syndrome. ${ }^{18}$
During HIV infection abnormalities in thyroid include both pathological changes and disturbances in its function. ${ }^{11,19}$ Our present study shows that thyroid dysfunction is frequent in HIV infection and with progression of disease there is a subclinical hypothyroid like stage that occurs in patients with advancing HIV infection. ${ }^{20}$ Various thyroid function tests such as FT3 /FT4 /serum TSH can be used as a surrogate marker as these correlate with the progression of the disease. One should not start upon the replacement therapy for hypothyroid like state in HIV infection, as the state may be responsive to highly active antiretroviral therapy. Our present study may give the true picture of thyroid abnormality in HIV-AIDS patients. To conclude, abnormal TFTs are encountered often in HIV infection and AIDS patient's individuals. Management guidelines exist for overt dysfunction as described above. However, larger studies are needed to evaluate the prevalence and outcomes of mild thyroid dysfunction in HIV-infected patients and to formulate screening and treatment guidelines.

\section{Conflict of interest: none.}

\section{References}

1. Rasool ST, Tang H, Wu J, Li W, et al. Increased level of IL32 during human immunodeficiency virus infection suppresses HIV replication. Immunol Lett 2008; 117: 161167.

2. Branson B. Current HIV epidemiology and revised recommendations for HIV testing in health-care settings. J Med Virol 2007; 79:S6-S10.

3. UNAIDS Report on the Global AIDS Epidemic. UNAIDS $10^{\text {th }}$ Anniversary Special Edition, Geneva, 2006.

4. National AIDS Control Organization (NACO), Ministry of Health and Family Welfare. Natural History and Clinical Manifestation of HIV/AIDS Specialist Training and Reference Module Government of India, New Delhi; pp58: 2003. 
5. Anastos K, Lu D, Shi Q, et al. Association of serum lipid levels with HIV serostatus, specific antiretroviral agents, and treatment regimens. J Acquir Immune Defic Syndr 2007; 1: $34-42$.

6. Ducobu J, Payen MC. Lipids and AIDS. Rev Med Brux 2000; 21: 11-17.

7. Khiangte L, Vidyabati R K, Singh M K, Bilasini Devi S, Rajen Singh T, Gyaneshwar Singh W. Study of serum lipid profile in human immunodeficiency virus (HIV) infected patients. JIACM 2007; 8: 307-311

8. Grunfeld C, Pang M, Doerrier W, et al. Lipids, lipoproteins, triglyceride clearance and cytokines in human immunodeficiency virus infection and the acquired immunodeficiency syndrome. J Clin Endocrinol Metab 1992; 74: 1045-1052.

9. Lambert M, Zech F, De Nayer P, Jamez J, Vandercam B. Elevation of serum thyroxine-binding globulin (but not cortisol-binding globulin and sex hormonebinding globulin) associated with the progression of human immunodeficiency virus infection. Am J Med 1990; 89: 748-51.

10. Feldt-Rasmussen U, Sestoft L, Berg H. Thyroid function tests in patients with acquired immune deficiency syndrome and healthy HIV I- positive outpatients. Eur J Clin Invest 1991; 21: 59-63.

11. Jain G, Devpura G, Gupta BS. Abnormalities in the Thyroid Function Tests as Surrogate Marker of Advancing HIV Infection in Infected Adults. JAPI 2009; 57:508-510.

12. National AIDS Control Organization (NACO), Ministry of Health and Family Welfare. HIV/AIDS Specialist training and reference module government of India, New Delhi; 5-8: 2003.

13. Mullamitha SA, Pazare AR. Study of Lipid profiles in HIV infection. JAPI 1999; 47: 622-624.

14. Kereveur A, Cambillau M, Kazatchkine M, Moatti N. Lipoprotein anomalies in HIV infection. Ann Med Interne (Paris) 1996; 147: 333-343.
15. Rogowska-Szadkowska D, Borzuchowska A. The levels of triglycerides, total cholesterol and HDL cholesterol in various stages of human immunodeficiency virus (HIV) infection. Pol Arch Med Wewn 1999; 101: 145-150.

16. Sullivan PS, Hanson DL, Chu SY, Jones JL, Ward JW. The adult/adolescent spectrum of disease group epidemiology of anemia in human immunodeficiency virus (HIV)-infected persons: results from the multi state adult and adolescent spectrum of HIV disease surveillance project. Blood 1998; 91: 301-308

17. Harbol AW, Liesveld JL, Simpson-Haidaris PJ, Abboud CN. Mechanisms of cytopenia in human immunodeficiency virus infection. Blood Rev 1994; 8: 241- 250.

18. Quirino T, Bongiovanni M, Ricci E. Hypothyroidism in HIV infected patients who have or have not received HAART. Clin Infect Disease 2004; 38: 596-597.

19. Chiarelli F, Galli L, Verrotti A, di Ricco L, Vierucci A, de Martino M. Thyroid function in children with perinatal HIV Type 1 infection. Thyroid 2000;10: 499505.

20. Bongiovanni M, Adorni F, Casana M, et al. Subclinical hypothyroidism in HIV-infected subjects. J Antimicrob Chemother 2006:58; 1086-1089. 